\title{
Method of Handling the Atypical Situations Management through the Informational System
}

\author{
Șargu Lilia ${ }^{1 *}$, Coman Claudiu ${ }^{2}$ \\ ${ }^{1}$ Associate Professor, PhD University of European Studies of Moldova, Republic of Moldova \\ ${ }^{2}$ Professor, PhD Transylvania University of Brasov Romania
}

DOI: $10.36348 /$ sjbms.2019.v04i09.003 $\quad$ | Received: 15.08.2019| Accepted: 22.08.2019| Published: 29.09.2019

*Corresponding author: Șargu Lilia

Abstract

The issue of atypical situations is a management challenge in the globalized economic activity today. There are no economies in the world that are facing atypical situations, and their approach in the context of information system is a way of studying their behavior and possibility of settlement with the expected effects. The author as result from more research suggested that factors creating atypical situations macroeconomic have an established behavior with a positive impact of atypical situations arise where strategic development and also identified how efficient management by basing new management concept of atypical situations. In this context the author develops research and assesses the information system as a factor in solving atypical situations.

Keywords: atypical situation, management information system, communication process, solution management strategy.

Copyright @ 2019: This is an open-access article distributed under the terms of the Creative Commons Attribution license which permits unrestricted use, distribution, and reproduction in any medium for non-commercial use (NonCommercial, or CC-BY-NC) provided the original author and source are credited.

\section{INTRODUCTION}

Currently, the world is at a crossroads of radical changes in the economy, which is influenced by information technology, which has become the only and main engine for providing information. Effectively it is hard to realize just how this element became predominant, and more and more vital to all business processes. The economy is not seeking those that advocate the materials are given when more than we turn into a world of immaterial. These are quite experienced in financially when money is no longer a source material but virtual industrially when the human factor has disappeared almost entirely from the production, management level, when choosing the tasks delegated away, including for the information becoming one of the available user being hundreds or thousands of kilometers away from the source claimed. Without realizing it we went to computerization including at international level, but it already is our life in the current period and develop more intensely like an avalanche that will include increasingly more components. Under normal circumstances the information and skills form part of the systems, only with reference to their effective management or how diversified presentation, processing, transmission and storage. But this is our life already in the current period and develop more intensely like an avalanche that will include increasingly more components. Under normal circumstances the information and skills form part of the systems, only with reference to their effective management or how diversified presentation, processing, transmission and storage. but this is our life already in the current period and develop more intensely like an avalanche that will include increasingly more components. Under normal circumstances the information and skills form part of the systems, only with reference to their effective management or how diversified presentation, processing, transmission and storage.

\section{MATERIALS AND METHODS}

The research purpose is to establish the role of information system in assessing atypical situations as part of the market economy and determining effective management system for resolving their national practice, the Republic of Moldova.

The authors identified the following methods as appropriate: Synthesis of theoretical, the argument of the problems addressed by the tabulation generalization 
hypothesis, the graphical representation of the theory proposed, for the deduction of the mathematical formula.

\section{RESULTS AND DISCUSSIONS}

Important topics addressed summarizes the information management of many management actions they are decisive, organizational selectively motivation, etc. All these actions are based on accuracy and quality of information provided or develop mathematical models that will allow solving problems, assist managers in decision-making, etc. New perspectives of management information systems through offers opportunities for progress at micro and macro level. Obviously, the role of information sources in atypical situations is quite high and in some way a constraint under uncertainty. If we refer to the information system, it is a separate component that develops parallel to and intersecting the management activity per assembly in the management processes. Information system under current conditions not only provide the information requested but enables structural analysis and in some cases is a fundamental strategic dimension of theoretical and practical. Regardless of how the information is transmitted, its use in terms of management at all levels and enables other processes conditioned by solving everyday problems. Given the current information system besides the role and timeliness that is, it brings together more interdependent elements such as:

- Data - are symbols in the form of letters, numbers or images can be represented individually or as a whole and can be perceived by the individual. In terms of economic and management data are or quantities that are the result of actions or events.

- Information - are some data that expresses the reality and reduces the uncertainty factor on events. Not all information becomes relevant to all applicants, only where the need was saturated.

- Information flow - is a route traveled by the recipient information. They have no way planned, only occurring during the work and can move between different management levels.

- Information flows - are a range of information that role to browse the information circuit. Depending on the mode flows in the circuit can be vertical, horizontal or oblique.

- Information procedures - are expression methods and techniques of information.

- Means treatment of information - is the physical means to support methods and techniques for collecting and processing information.

The relevance of information is denoted from its usefulness in the management process and the quality is given the complexity of the information. Addressing information and information system management background and atypical situations summarizes the context of solving atypical situations arising in the macro. Whatever the scope and type of atypical situation, the engine will be the settlement information system team consists remedies atypical. The role of the information in the settlement of the atypical situations in figure 1 can be constant.

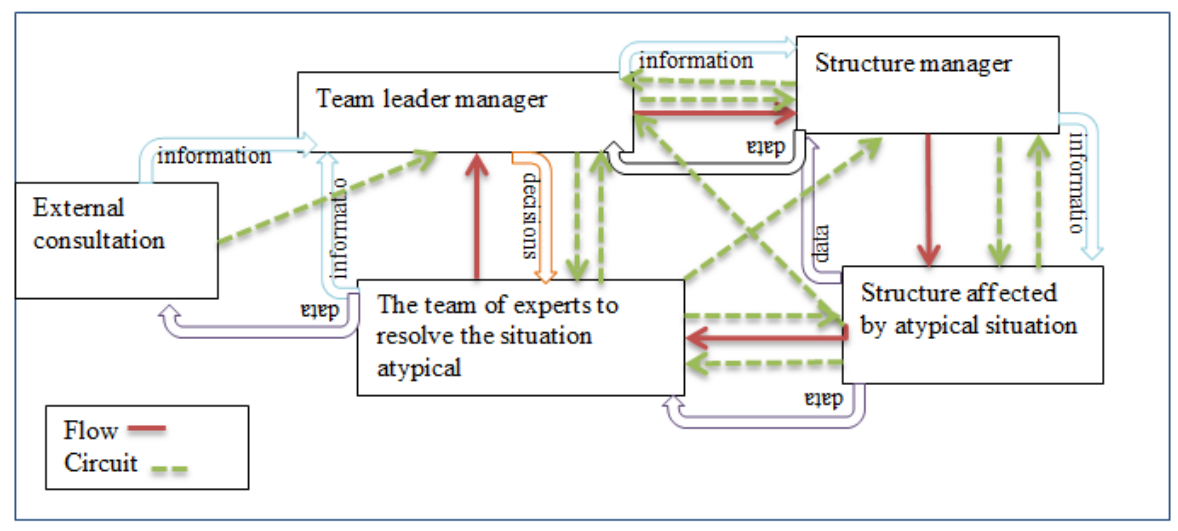

Fig-1: The process of solving atypical situations in the context of information system

Peculiarities information management atypical situations manifests itself in two ways: the purpose and process. Addressing information is considered as the object support and circuits used in information flow shown in Figure 1. The transfer of data is performed in a conventional manner from the receiver to the receiver in several ways physical, human or electronic. Despite the circumstances and the current period method of transmitting information object addressed as the information is often electronically. This prevents transmission and nonverbal messages, emotions, reactions to it. Approach to process information is limited to a process in which both the transmitter and receiver can intervene and modify data in the formulation of an integrated message.

The process of communication both internally and with the external environment plays an important role in atypical situations. Because atypical situations as an area still little studied, and their management processes management is still at the initial stage it will be quite difficult to identify specific communication processes. It is worth mentioning the importance of effective communication relationships and effective 
settlement conditions atypical situations. According to the formula of success of solving atypical situations, identify the main actors of the communication process. Thus, the process of communication these conditions will have some distinctive features compared with other communication processes management. In this context we mention Minodora Ursăcescu triangle, that in the communication management and exchange of information through the process-based approach identifies three poles of interest [1] information - the action - the individual. The role being played by the fact that information is used and produced some contexts such as economic, social, organizational, etc. Action role playing any information that can produce human activities and they are timed finals determined. Role playing individual perception of information by each individual in particular. Action role playing any information that can produce human activities and they are timed finals determined. Role playing individual perception of information by each individual in particular.

Collecting information in the context of each individual measure of performance, skills and necessary approach to information system will be based on subjective value issues and the relative. Any information disseminated is a perception first transmitter and a second receiver, depending on the necessity that can interpret completely different source transmitters. Ideally, the message to be transmitted and interpreted identically, except that certain circumstances cannot provide it. The role of information in the context of solving atypical situations is to enlighten and help resolve the issue. Thus, the author finds requirements for information solving atypical situations. Table 1 presents information peculiarities and characteristics.

Table-1: Peculiarities of the information provided in special situations

\begin{tabular}{|l|l|}
\hline $\begin{array}{l}\text { Information } \\
\text { particularities }\end{array}$ & Information features \\
\hline Complexity & $\begin{array}{l}\text { Manifested by the versatility of proving to become relevant. In fact, this feature cannot be } \\
\text { achieved within as demonstrated by the losses in the flows and circuits. }\end{array}$ \\
\hline Accuracy & $\begin{array}{l}\text { It expressed its information content and origin. Accuracy of information gives specific } \\
\text { functionality. This feature can naturally lose value is affected by time. }\end{array}$ \\
\hline Accessibility & $\begin{array}{l}\text { It is manifested by being able to be found easily, and how to benefit from this information is } \\
\text { the time of application. Access is free and available at any time. }\end{array}$ \\
\hline Opportunity & Information uncertainty applicant to provide the possibility of settling in certain circumstances. \\
\hline Relevance & $\begin{array}{l}\text { Information should meet expectations and contribute to highlighting the doubt or ignorance. } \\
\text { Be marked to meet expectations. }\end{array}$ \\
\hline Time & $\begin{array}{l}\text { The information to be provided in a timely or timely. This possibility of being contacted in the } \\
\text { required time frame gives the possibility to use at the right time and at the right time chance. }\end{array}$ \\
\hline Reliability & $\begin{array}{l}\text { Feature to operate without distortion over time and in given conditions. The information must } \\
\text { be secure. }\end{array}$ \\
\hline
\end{tabular}

Source: prepared by the author based on the references

The information provided for special situations cannot be relative character, which would put at risk the right decisions, while the team of experts is under contract by the parties affected and cannot impose his own opinion, but only one correct. The role of information for solving atypical situations is considered to be one of reducing uncertainty and creating the phenomenon of reality makes it possible to solve the problem [2]. The issue of reducing uncertainty using information is a subject quite so current world of mathematicians and computer scientists, who proved the theory of the phenomenon of "information entropy" [3], which is a phenomenon Gage. Most economic phenomena are not controlled nor occurs cyclically or ordered, that they cannot be formed as remotecontrolled systems. According to the study by $\mathrm{C}$. Shannon "to measure the significance of the information is not important but the amount they" summarizes the uncertain economic phenomena, to reduce uncertainty regarding the manifestation of the phenomenon requires a corresponding amount of information. In this context information to determine entropy atypical situations as an indicator expressing uncertainty expressed by the average amount of information obtained reflected a certain probability of influencing factors. Shannon's theory using the following formula set information entropy of atypical situations where:

$$
E_{a}=\sum_{k=1}^{n} p_{k} \log _{2} p_{k}
$$

Where:

$E_{a}$ - informational entropy atypical situations

$p_{k}$ - factors influence the probability of $\mathrm{k}$, where $\mathrm{k}=1,2,3, \ldots \mathrm{n}$.

Information entropy atypical situations are an indicator of the amount of information opposite. If uncertainty is saturated when the amount of information is smaller because it reflects the balance phenomenon.

In the communication process and accumulation of data and information for the settlement of atypical situations identifies formal and informal information. Conjuncture formal data includes plans, projects, programs, strategies, processes, and value 
indicators etc. which have an important role in making management decisions. Informal information is given to the reality of economic, financial, political, social, innovation, etc. presented separately or in combination.

\section{CONCLUSIONS}

Information flows used in the identification process - control atypical situations being analyzed allowed the authors to express the distinctive characteristics, which will allow their classification management system and assigning degrees of importance. Such notes that information about the possibilities for solving various situations created by informal factors of interest for later reference and is considered precious experience, comparison and Subsequent treatment situations.

As a result of theoretical and applied research to the role and functionality of information flow management context atypical situations, and in the measurement of economic phenomena affected by these situations authors deduced using theories of Shannon information entropy of atypical situations.

In the context information management decision making situations created by various factors, etc. It needs to be capitalized for assessment. In these circumstances call system formed three-dimensional data - information - skills. These are characteristics that members of the expert team and manager team leader. With more experience in solving atypical situations team of experts will more likely you are to solve the most difficult and complex atypical situations. The knowledge gained from experience by team members solving atypical situations is a unique source of strategic management spectrum of situations particularly atypical micro and macro level.

\section{REFFERENCE}

1. Ursăcescu., Minodora. (2009). Information and knowledge economy, Bucharest University Publishing House, 78.

2. Coman, C., (2011). Statistics applied social sciences, Iaşi: European Institute, 392

3. Learning and organizational bounded rationality, HERBERT A. SIMON http://digitalcollections.library.cmu.edu/awweb/aw archive?type $=$ file \&item $=34126$

4. Şargu, L. (2017). Management of atypical situations, In: Universe sciences Iasi, 8:156-160

5. Şargu, L. (2018). Management of atypical Situations through the quality management system in: the collective Monograph Management of innovative development the economic intension, Poland, 198-208. 